\title{
The Effect of Service Failure on Customer Switching Intention in the Tourism Industry
}

\author{
Li-mei Hung, Yueh-shian Lee* \\ Department of Hospitality Management, HUNGKUANG University, Taiwan
}

Copyright (C) 2015 by authors, all rights reserved. Authors agree that this article remains permanently open access under the terms of the Creative Commons Attribution License 4.0 International License.

\begin{abstract}
As people's standard of living has increased, tourism's is taking a greater share in peoples' consumption. The tourism market continues to expand; however, customers' complaints became more frequent, travel agencies and tourists had more disputes, and there have been increased service failures of travel agencies. Therefore, how to reduce customers switching intention became one of the critical issues. This study investigates the effect of service failures on customers switching intention and personality traits. The results showed that travel agencies notify customers reservation cannot be made due to insufficient number of participants before departure have no effect on the customer switching intention. Service failure on the journey about important attractions unable to visit or must cancel the attractions journey or tour guide provides poor service effect on the customer switching intention.
\end{abstract}

Keywords Service Failures, Customers Switching Intention, Personality Traits, Tourism Industry

\section{Introduction}

\subsection{Research Background and Motivation}

According to the MOEA Statistics Department statistics, the GDP proportion of $73.27 \%$ in the services industry in the fourth quarter of 2014, which indicates that the service industry has become main industry of Taiwan. According to the Traffic Bureau of Tourism, tourism policy (Traffic and Tourism Bureau Statistics, Executive Yuan, 2014) promoting the "Top Sightseeing Pilot Program". The development of international tourism, enhancing the quality of tourism and increasing foreign exchange earnings allow the world to see Taiwan's new charm. In 2009, 8,142,946 people traveled abroad. In 2013, the number of tourists travelling abroad was $11,052,908$. The number of people travelling abroad is growing quite fast. The service industry in developing countries played an important role in the economy, roughly accounting for the percentage of gross domestic product (GDP) by more than half. Economic growth and service sector employment increased. However, service failures are usually among customers' subjective judging points (Lewis \& Spyrakopoulos, 2001). A Service failure occurring in Situation 1, when the travel agency cannot deal with the customers' problems immediately, often makes customers angry. When customers become angry, the anger turns into dissatisfaction and complaining, especially regarding the service failure, which is the most common complaint of unsatisfactory service experience. It is the main reason why customers choose to purchase from other service providers (Lin, 2011). The disputes between customers and travel agents have greatly increased leading to failures of travel agency services. Previous studies found that customers' change their intentions up to $68.1 \%$ of the time, which is more than twice the number of customers who never consider changing travel agencies. Thus, customers switching intention become a serious problem (He, 2008; Manhas, 2013).

Ganesh et al. [7] believed customers' considered service quality that the travel agency provide, after customers finish their trip, directly affect the switching intention, post-purchase evaluation is reflected in the satisfaction and brand identity. With awareness and rights increasing, more customers confront service failures or unsatisfactory services, and future complaints of customers increase (Chou, 2015). If the travel agency is unable to deal effectively with customer dissatisfaction, the agency may lose customers. Customer complaints may also cause the loss of potential customers (Ling, 2000). Kim [16] believed that when customers change their intention businesses lose the opportunity to earn the potential profit, and lose the costs associated with resources wasted on the customers' maintenance costs. Companies must also spend extra costs to attract new clients to substitute for customers who changed their intentions (Konus, 2014). Athanassopoulos, Gounaris, and Stathakopoulos [1] discussed customers switching intentions by way of customer satisfaction studies. This research found factors which influence customers 
switching intention as follows: service quality, price, convenience, innovation and customer satisfaction. Grace \& O'Cass [10] concluded that consumers switching intention in the service industry result in decreasing market share, declining profits and business losses or other negative effects in the future. It is the importance of avoiding customers' switching intention on business operations, so today's enterprise must not only consider how to provide services to customers, but also remedy service failures. Thus, customer dissatisfaction can be reduced and may even improve customer loyalty.

\subsection{Purpose}

This study investigated the relevance of customer personality and travel agency service failure on whether the customer switches intention. The research results help managers and researchers understand the real reasons why customers switch intentions and aid in improving and developing a strategy for dealing with the problem of customers switching intentions. Based on the research background and motives, the following purposes are listed

1. Explore the relationship of customer service failure on the customer switching intention.

2. Explore the effect of personality traits on customer switching intention.

3. Explore the effect of customer service failure on customer switching intention through personality traits

\section{Literature Review}

\subsection{Service Failures}

A service failure occurs when services or products provided by companies do not meet customers' needs or standards (Zheng, 1997). The customer determines that something is wrong and uncomfortable (McMullan, 2000). Even under the high standard requirement, even when the service provider performed without error, customers would react and complain, alleging service provider mistakes $(\mathrm{Wu}$, 2002). Service failure is service performance "below customers' expectations or tolerance range" (Holloway and Beatty, 2003) as a definition. These mistakes will cause the enterprise the loss of customers or increase negative reviews, as well as service failure is one of the major factors contributing to customers switching intention (McCollough et al, 2000). In such a case, making the appropriate service remedy to soothe customers' emotions, remedying for service failures which caused relationship rifts becomes a very important issue (Zho, 2004; Wu, 2002). Therefore, actively minimizing service failures is the long-term business operating method. That is, not only should remedy be taken to improve service errors, more importantly, business strategy should include that "prevention is better than cure", including staff training and the establishment of a customer feedback system (Ling, 2004).

Because the service industry deals with intangibility, inseparability, variability and heterogeneity, in the process of providing services it is impossible to achieve zero error (Panda, 2014; Fuentes, 2012). Priluck (2003) considered that customers dissatisfied with service providers may terminate the business transaction, or provide negative reviews (Chang, 2015), both of which cause damage to the enterprise. Zheng Shaocheng, Wu Jiajie (2003) noted that the gravity of the service failure will cause halo effect and domino effect of two properties. The "halo effect" is used to refer to small failure, but because of different understandings and "Domino effect" refers to the cumulative effect produced when one event sets off a chain of events. The service failure is due to other service delivery process errors.

Service process and service control cannot be tested to ensure quality of service. Moreover, because the travel services provider product relies on person to person contact and interaction to complete, in a complex situation under the influence of all, the service is almost impossible to keep consistent (Wu,2008; Schenfeld, 2014). For the travel agency industry, service failures virtually inevitably occur (Yin, 2008). Therefore, understanding the importance of travel agency service failure and remedy, and building a service recovery system for travel agencies, are critical to improve service systems for travel agencies (Wu, 2008).

\subsection{Customers Switching Intention}

The switching of consumer intentions refers to customers rejecting a product or service in favor of a competitor's. For example, a customer might never return back for second time purchase if he is dissatisfied with the customer service the first time. Consumer switching intention presents danger for a business. If retailers do not keep their customer satisfied, competitors might directly benefit (Kim, 2012).

Ping (1993) and Zeithaml, and Berry (1996) defined customer's switching intention is customer's strong emotional reaction and relationship dissolution, whereas other behaviors create a predisposition to switch.

Athanassopoulos, Gounaris, and Stathakopoulos [1]investigated switching intentions from views of customer satisfaction, and explored the Greek banking service industry. Their research found customer switching intention factors as follows: service quality, price, convenience, innovation and customer satisfaction. Ganesh et al. [8] argued in customer switching intention factors, customers using the products or services generated by the post-purchase evaluation, will directly affect the switching intention of customer intent. Post-purchase evaluation is reflected in the satisfaction with the product and brand identity. But sometimes the influence of social environment than a personal attitude; in addition, individual willpower, if weak, is likely to make external factors that interfere with personal intentions. Switching intentions refers to the 
termination of the relationship between the customer and vendor (Bansal, Irving, \& Taylor, 2004). Switching intention can be defined as anger incidents, primarily it occurs when the customer decides to terminate the purchase of major services. Ye [35] pointed out that competitor's behavior is not the main reason for a customer switching intention, rather it is that the customer is not completely satisfied with the low firm commitment, poor service or price unfairness.

\subsection{Personality Traits}

"Personality," is derived from the Latin "persona", referring to a theatrical mask and its implications, including the eyes of others, who saw their side, as well as the characteristics of individuals, containing many subjective social or emotional traits, something which cannot be seen directly Personality will continue to influence the behavior of individuals in different conditions, and also inner self motivation, and attitudes (Lin, 2006). Hu Menglei [15] , defining personality trait: "individual behavior, reflecting their unique personality traits, when these features appear in different contexts are referred to as personality traits." $\mathrm{Li}$ Xuexiu (2005) explained that the different personality formation is influenced by the temporal and spatial environment, personal experiences, and cultural differences will affect the individual's ideas and decisions. Personality is a combination of unique personal attributes and characteristics (Liao, 2005).

Guo Yixin [12] thought that personality traits are influenced by personal background and the social environment of the individual including the stimulus impact of the internalization of response, and this response will continue to appear on an individual's personality, making this characteristic immutable. Personality traits proposed by some scholars that used to represent an individual's thoughts, feelings, and behavior patterns, and individuals will express in different ways at certain times based on their individual traits. (Hong, 2010). The scholars described above conclude: a collection of personality traits represented by individuals' ways of thinking, acting, and reacting, in ways that reflect each individual's unique personality traits and that even in different contexts this unique personality appears.

\subsection{Locus of Control}

Locus of control and personality traits in psychology. The concept was coined by Julian Rotter in the 1950's and has since become an important aspect of psychological study. A person's locus is conceptualized as either internal or external. The person believes either that they can control their life or that their life and decisions are controlled by environmental factors which they cannot influence, or by fate. Individuals with a strong internal locus of control believe events in their life derive from their own actions. They believe success comes from the efforts of individuals; failure is their own responsibility. People with a strong external locus of control tend to blame external factors for their failures. People with high external locus of behavior believe that their behavior is a result of external influence.

\section{Methodology}

\subsection{A research Framework}

Using the study of personality traits, service failures, and the switching of customers' intention, of the literature review and the relevance of the analysis, a framework of this study was made, as shown in Figure 1.

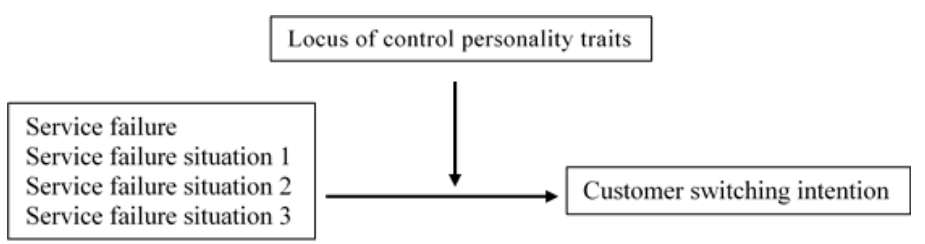

Figure 1. A research framework

Situation 1: travel agency notifies customer that a reservation cannot be made due to an insufficient number of participants three days before departure (before the trip).

Situation 2: during the journey, important attractions are unable to be visited or the attractions must be cancelled (during the trip).

Situation 3: during the journey, a tour guide provides poor service (during the trip).

3.2 Research hypothesis

According to the study framework the following assumptions were made:

Hypothesis1: Service failure will increase the switching of customer's intention.

Hypothesis2: Locus of control personality traits significantly influenced whether the customer switched intention.

Hypothesis3: Locus of control personality traits indirectly effect service failure and switching of customer intention.

\subsection{Participants and Sampling Methods}

Residents of central Taiwan were sampled with two conditions, which were the use of a travel agency and who participated in the overseas package tour, are the objects to be discussed in this study. The study is designed to learn more about personality traits, service failures and switching of customer intention.

This study used convenience sampling techniques and paper questionnaires. Before distributing questionnaires, participants were contacted to make sure the participants understood the content and purpose of the research. Participants were then asked to fill out the questionnaire items individually. 


\subsection{Data Analysis Method}

According to the study of structure and assumptions, incomplete questionnaires will not be included. Using the statistical software SPSS18.0 for data analysis, the study of statistical methods used are as follows:

\subsubsection{Reliability and validly analysis}

Reliability refers to whether the measurement has a degree of consistency or stability. This study used Cronbach's $\alpha$ value to measure of internal consistency, that is, how closely related a set of items are as a group. It is considered to be a measure of scale reliability. According to Guieford [11], if Cronbach's $\alpha$ coefficient is greater than 0.7 the study presents very high degree of reliability and a good questionnaire design. If the $\alpha$ coefficient values from 0.35 to 0.7 the questionnaire is in an acceptable range. If the $\alpha$ coefficient is less than 0.35 there is low reliability. This represents poor questionnaire design, and the question should be deleted.

\subsubsection{Descriptive statistics analysis}

The discipline of quantitatively describes the main features of a collection of participants or the quantitative description itself. Descriptive statistics aim to summarize a sample, rather than use the data to learn about the population that the sample of data is thought to represent.

\subsubsection{Simple regression analysis}

With simple regression we test the cause and effect of service failures, locus of control, and switching of customer intention.

\subsubsection{Hierarchical multiple regression analysis}

This research used hierarchical multiple regression analysis, explored service failure to switching of customer intention, and then added the locus of control to service failure for interaction of service failures. Observed interactions in the regression procedure $\beta$-value are significant in order to verify whether the locus of control personality traits with mediation.

\section{Research Analysis and Results}

\subsection{Service Failure of Reliability and Validity}

Validity analysis using factor analysis in this study, estimates of factored loads using the principal component method, and with the greatest variation method for shaft, filtered 3 factors with a characteristic value greater than 1 to measure service failures. After factoring analysis of items, delete the third item in the third factors, first and second factors of items full retained, so this part of the items from originally of 9 items reduced became 8 items, again according to each factors of items. Those factors respectively named for "service failure situation 3 ", "service failure situation 2", and "service failure situations 1". Service failure scale of KMO value 0.701, ball-type verification of approximate chi-squared distribution 921.215 , significant 0 , reach significantly, were selected by 3 factors, cumulative variance accounted for up to $77.267 \%$, shown in table 1. Total reliability of service failure dimensions Cronbach's $\alpha$ coefficient of 0.825 , service failure situation 3 ,Cronbach's $\alpha$ coefficient for 0.831.And service failure situation2, Cronbach's acoefficients for 0.820 are up to 0.70 present very high reliability, only a service failure situation 1Cronbach's $\square$ Coefficients for 0.673 , although not above then 0.70 . Remain moderate reliability, in an acceptable range. Shown in table 1.

\subsection{Customers Switching Intention of Reliability and Validity}

Validity analysis using factor analysis of this study, estimates of factored loads using the principal component method, and with the greatest variation method for shaft, filtered 3 factors with a characteristic value greater than 1 to measure customer switching intention. Items after factors analysis, delete the third item in the third factors, the first and the second factors of items full retained, so this part of items from originally of 9 items reduced became 8 items, then according to the relationship of each factors, those factors respectively named for "switching intention situation 3", and " switching intention situation 2", and " Switching intention situation 1 . "Switching intention scale KMO value for 0.594 , ball-type verification of approximate chi-squared distribution 462.203, freedom28, significant 0.000 reach significantly, were selected by 3 factors, cumulative variance accounted for as much as $66.063 \%$, as shown in table 2.

The research dimension of switching intention a total reliability Cronbach's $\alpha$ coefficients is 0.693 .And switching intention situation 2 Cronbach's acoefficients for 0.673.And switching intention situations 1 Cronbach'sacoefficients for 0.629 , are not above then 0.70 , which is still moderate reliability, said the questionnaire in the acceptable range, switching intention situation 3 of Cronbach's acoefficients for 0.736 , Up to 0.70 , very high reliability, such as a table 2 .

\subsection{Locus of Control of Reliability and Validity}

Locus of control scales refers to Ke Chunyi (2007) quoted from Spector [29] , modifying from Rotter's research scale in1966, a previous study from Ke Chunyi (2007), Xu Fengqing (2009), Sun Aini (2010) verified Cronbach's aabout 0.7, presenting good reliability, thus ensuring that content validity.

Locus of control items all were retained in this study, it KMO for 0.786 Cumulative explained variance $53.580 \%$, there are more than $50 \%$, although the explained variation is not great enough, but is acceptable. Ball-type verification of the approximate chi-squared distribution 805.484, degrees of freedom are 120 , significant 0.000 , significantly, its 
dimensions total reliability Cronbach's $\alpha$ coefficients of 0.693, although not reach 0.70 . Remain moderate reliability, within an acceptable range.

\subsection{Descriptive Statistics Analysis}

Descriptive statistics were used to analyze sample, to understand their distribution and characteristics.

\subsubsection{Questionnaires}

This study distributed 461 paper questionnaires to participants who patronized a travel agency in Taiwan. 451 questionnaires were collected, excluding 39 incomplete and invalid questionnaires. The study included a total of 412 questionnaires. The total effective response rate was $91.35 \%$.

\subsubsection{Sample analysis}

A total of 195 People, number of valid questionnaires for 47.3\%. Gender: Among the effective questionnaires, women accounted for the majority, namely 222, accounting for $53.9 \%$ of the number of valid questionnaires. Age: $31-40$ years of age there were 159 people, accounting for $38.6 \%$ of the number of valid questionnaires.

Education: The majority of participants, 251 people, held a University degree accounting for $60.9 \%$ of the number of valid questionnaires.

Average monthly income: the average monthly income distributed to $30,000-40,000$ majority, a total of 102 people, accounting for $24.8 \%$ of the number of valid questionnaires.

Occupation: Professional subjects, mostly in the service sector, a total of 136 people, accounting for $33 \%$ of the number of valid questionnaires (see table 3 ).

Usually multiple people participate in an overseas tour: The majority of participants travelled with a spouse, a total of 225 people, accounting for $34.1 \%$ of valid questionnaires.

\subsection{Research Hypothesis and Verification}

Regression analysis is mainly used to test two numeric-type variables in a cause and effect relationship, help us to verify hypotheses to be true, regression analysis in this section explores the relationship between service failures on customers switching intention, and mediate the effects of locus of personality traits on service failure and customers switching intention.

\subsubsection{The relationship of the service failure on the customer switching intention}

Service failure situation 1 on a customer relationship switching intention: this study used regression analysis to detect service failure situations 1 on switching of customers' intention. The analysis results are shown in table 4. Regression analysis showed that service failure had no significant effect on customers switching intention (the coefficient value was 0.22 , not significant). This shows service failures in situation 1 will not increase the switching of customer intention, that is, if travel agencies inform the customers prior to three days before the departure date, due to the fewer number of participants this does not affect customers switching intention on travel agents.

Service failure situations 2 on a customer switching intention:

This study used regression analysis to detect service failures in situations 2 on switching of customers' intention. The analysis results are shown in table 5. In service failure situations 2, customers tend to have a positive and significant effect (coefficient470, $\mathrm{p}<0.001$ ). This shows that service failure in situation 2 will increase the likelihood of a customer switching intention; so hypotheses $1-2$ is supported; that is, when travelers join the tour and the travel agency is unable to provide the promised activities or cancels the promised journey, this causes customers to be more likely to switch their intentions.

Service failure in situations 3 with a customer switching intention: this study used regression analysis to detect service failures in situation 3 on customers switching intention. The analysis results are shown in table 5. From regression analysis, service failures in situation 3 have a positive and significant effect on the switching of customers' intention. (Coefficient.452, p<0.001) shows service failures in situation 3 increase the likelihood that customers will switch intentions, so hypothesis1-3 is supported. During the tour, service failures that occur, such as the poor attitude of the tour leader or tour guide, are more serious, and cause customers to switch intentions more often.

\subsubsection{The mediated effect of locus of control on service failure and customers switching intention}

The mediated effect of a service failure (situation 1) on customers switching intention through locus of control

Analysis results in table 4, from the multiple regression analysis, locus of personality traits to service failures on the customer switching intention does not have a mediated effect (Coefficient of 0.14, not significant). When travel agencies notify customers, at least 3 days prior to their departure that the customers are unable to tour due to an insufficient number of participants, the service failures have no significant effect on the switching of customer intention through locus of control.

The mediated effect of a service failure (situation 2) on customers switching intention through locus of control

Analysis of results such as table 4, from the multiple regression analysis, locus of control of service failure situations 2 to the customer switching intention does not have a mediated effect (coefficient value of 0.152 , not significant), Joined locus of control, in the travel, the travel agency unable to tour inside the important attractions, or must cancel the tour, the service failures have no significant effect on the customer switching intention.

The mediated effect of a service failure (in the situation 3 ) 
on customers switching intention through locus of control, in table 4 . From the multiple regression analysis, locus of control to service failure situations 3 on the customer switching intention does not have a mediated effect (Coefficient value is-0.298, not significant). Research hypotheses 3-3is not supported, which joined the locus of control adjustment, while the customer is travelling, agency or tour guide service failures have no significant effect on whether the customer switches intentions.

\subsubsection{The Effect of Locus of Control on Customer Switching Intention}

Situation 1: The effect of locus of control on customer switching intention

This study used regression analysis to detect locus of control influence on customers switching intention, in table 6. Locus of control has no significant effect on customers switching intention in situation 1 (coefficient 0.53 , not significant). Locus of control to customers switching intentions has no significant positive effect when travel agencies inform customers that they are unable to tour due to an insufficient number of participants three or more days prior to the departure date.

Situation 2: The effect of locus of control on customer switching intention

In table 5, the results of regression analysis show that the locus of control has no significant impact on customers switching intention in situation 2. (Coefficient value is 0.72 , not significant). Locus of control to customers switching intention has no significant positive effect when, during the trip, clients are unable to enter important attractions, or when they must cancel visits to scenic spots does not significantly affect customers switching intention.

Situation 3: The effect of locus of control on customer switching intention

In table 5, from regression analysis that the locus of personality traits have no significant effect on customers switching intention in situation 3 (Coefficient of 0.70 , not significant) show locus of control to customers switching intention in situation 3 has no significant positive effect Therefore, hypothesis 2-3 is not true; that is, service failures that occur in the form of the poor attitude of a tour leader or tour guide will not significantly affect the customer switching intention.

\subsection{Discussion}

This section will focus on the hypothesis and regression analysis to verify results and notes compiled in table 6 .

Based on the above assumptions, we verified the research. Hypothesis 1-2 and hypothesis 1-3 are established. That is. service failures in situation 2 and in situation 3 have positive effects on customers switching intention. A service failure during the trip, such as the travel agency is unable to tour important attractions or must cancel visits to scenic locations, and service failures such as the poor attitude of a tour guide could easily lead to customers switching intention. These are the service failures in situation 2 or situation 3 which are likely to increase the chances that the customer will switch intention.

However, based on the above assumptions the hypothesis 1-1, hypothesis 2-1, hypothesis 2-2, hypothesis 2-3, hypothesis 3-1, hypothesis 3-2, and hypothesis 3-3 are not established. The possible causes are as follows:

\subsubsection{Hypothesis 1-1 not established; 1-2, 1-3 established}

Research shows that travel agency service failures have no significant effect on customers switching intention in situation 1. Possible reasons for this include that when travel agency service failures occur prior to the tour date, the agency may remedy the situation by providing service, apologies, discounts, gifts, full refund, housing upgrades, and other ways, significantly reducing the chance that customers will switch intention.

\subsubsection{Hypothesis 2-1, 2-2, 2-3, not established}

The research results showed locus of control has no significant effects on customers switching intention. Possible causes include that people with internal personality traits, which cause them to believe that they can control their own fate. These people evaluate each aspect of a result, and then make a decision, so internal personality traits have no significant effect on the whether the customer switches intention. People with external personality traits, who lack confident, and may easily be effected by others' bad evaluations of the travel agency may allow others' decisions to affect their own decision on whether or not to transfer to another travel agency, so external personality traits on the customer switching intention also have no significantly effects.

\subsubsection{Hypothesis 3-1, 3-2, 3-3, not established}

Research shows locus of control on the service failure to the customer switching intention has no significant effect. That means locus of control personality traits on service failure to the customer switching intention do not have a mediated effect. Possible reasons include that the travel agency's service failure was within the customer's tolerance range before the departure date or the possibility that the customer did not consider transferring to another travel agency. If travel agency service failures are serious, and occurred during the trip, for example, customers cannot visit important attractions, or a tour guide has a poor attitude, these service failures cannot be remedied to the customer's satisfaction, which could easily increase the chance that customers switch intention. So the seriousness of travel agency service failures is a major reason for customers switching intention, personality traits are not associated with customers switching intention, so locus of control personality on service failures to customers switching intention does not have a mediated effect. 


\section{Conclusions and Recommendations}

\subsection{Conclusion}

This study has three main purposes: to explore the relationship of service failures on the customer switching intention; to investigate the influence of personality traits on the customer switching intention; whether personality traits have a mediated effect of customer service failures on customers switching intention. This research finds that a service failure in situation 1 will not cause the customer to switch intention. Locus of control does not have a significant effect on customer switching intention. And, locus of control does not have mediated effect to service failure on the customer switching intention. This research result shows that the service failures of travel agents who are unable to provide the important attractions or must cancel the attractions (situation 2), or service failure caused by the poor attitude of a tour guide (situation 3), could easily lead to the customer switching intention. The research results are supported by previous studies of service failures which caused the customers to switch intention, but also through the locus of control discussion of the personality traits. In terms of theoretical implications, research shows service failures in situation 2 and situation 3 have a positive effect on whether customers switch intention. This shows that customers believe travel agency service failures in situation 2 and in situation 3 will increase switching intention. The research results found service failures on customer switching intention are significantly affected when the situations occur during the trip. However, the service failure has no significant effect on the customer switching intention when the failure occurred three days before the departure date. In the past, studies about service failure on customer switching intention, especially for travel agency service failures. Therefore, the results of this empirical study can be used as corroboration and as a reference for future researchers to explore the relevant issues.

Furthermore, previous studies related to service failures on customers switching intention exclude discussion of mediating factors. This research finds that locus of control personality traits to service failure do not have a significant effect on customers switching intention.

\subsection{Recommendation}

In terms of practical implications, the research results show that a service failure in situation 2 and in situation 3 has a positive effect on customers switching intention. The research results mean that customers deeply consider trip planning, especially for visiting important or famous attractions, so travel agencies should not arbitrarily change a journey to customers' disappointment. Also, during the trip, if customers encounter a tour guide with a bad attitude, or customers' opinions were ignored, these negative behaviors cause customer complaints which spread a negative reputation, and cause customers to consider a different travel agency for their next tour. These research results suggest travel agencies should consider upgrading service quality, focusing on the arrangements of the trip, and focus on orienting customer service to reduce the chance of the customer switching intention.

Table1. Service failure of reliability and validity

\begin{tabular}{|c|c|c|c|c|c|c|c|}
\hline \multirow{2}{*}{$\begin{array}{l}\text { Preliminary questionnaire } \\
\text { questions }\end{array}$} & \multicolumn{3}{|c|}{ Factors } & \multirow{2}{*}{$\begin{array}{l}\text { Formal } \\
\text { questions }\end{array}$} & \multirow{2}{*}{$\begin{array}{l}\text { Cumulative } \\
\text { variance }\end{array}$} & \multirow{2}{*}{ Naming } & \multirow{2}{*}{ Reliability } \\
\hline & 1 & 2 & 3 & & & & \\
\hline 9 & 865 & 098. & -.051 & 8 & \multirow{3}{*}{$27.6 \%$} & \multirow{3}{*}{$\begin{array}{c}\text { Service failure in situation } \\
3\end{array}$} & \multirow{3}{*}{0.831} \\
\hline 8 & 85. & 230. & 152. & 7 & & & \\
\hline 7 & 777. & .023. & 490. & 6 & & & \\
\hline 6 & 077. & 912. & 046. & 5 & \multirow{3}{*}{$53.473 \%$} & \multirow{3}{*}{$\begin{array}{l}\text { Service failure in the } \\
\text { situation } 2\end{array}$} & \multirow{3}{*}{0.820} \\
\hline 5 & 185. & 852. & 291. & 4 & & & \\
\hline 4 & 236. & 553. & 537. & 3 & & & \\
\hline 1 & 176. & 051. & 911. & 1 & \multirow{2}{*}{$77.267 \%$} & \multirow{2}{*}{$\begin{array}{l}\text { Service failure in the } \\
\text { situation } 1\end{array}$} & \multirow{2}{*}{0.673} \\
\hline 2 & .011 & .375 & .657 & 2 & & & \\
\hline $\begin{array}{c}\text { Model } \\
\text { Fitness }\end{array}$ & \multicolumn{7}{|c|}{$\begin{array}{c}\mathrm{KMO}=0.701 . \text { Bartlett ball test: } 0.000^{* * *} \\
\text { Degrees of freedom 28 Approximate a Chi-square distribution } 921.215\end{array}$} \\
\hline $\begin{array}{c}\text { Dimensions } \\
\text { Total reliability }\end{array}$ & \multicolumn{7}{|c|}{0.825} \\
\hline Note & \multicolumn{7}{|c|}{$\begin{array}{c}\text { Parameter estimation based on principal component analysis, maximum variation method for shaft mining and } \\
\text { extraction values greater than } 1\end{array}$} \\
\hline
\end{tabular}


Table 2. Customer switching intention of reliability and validity

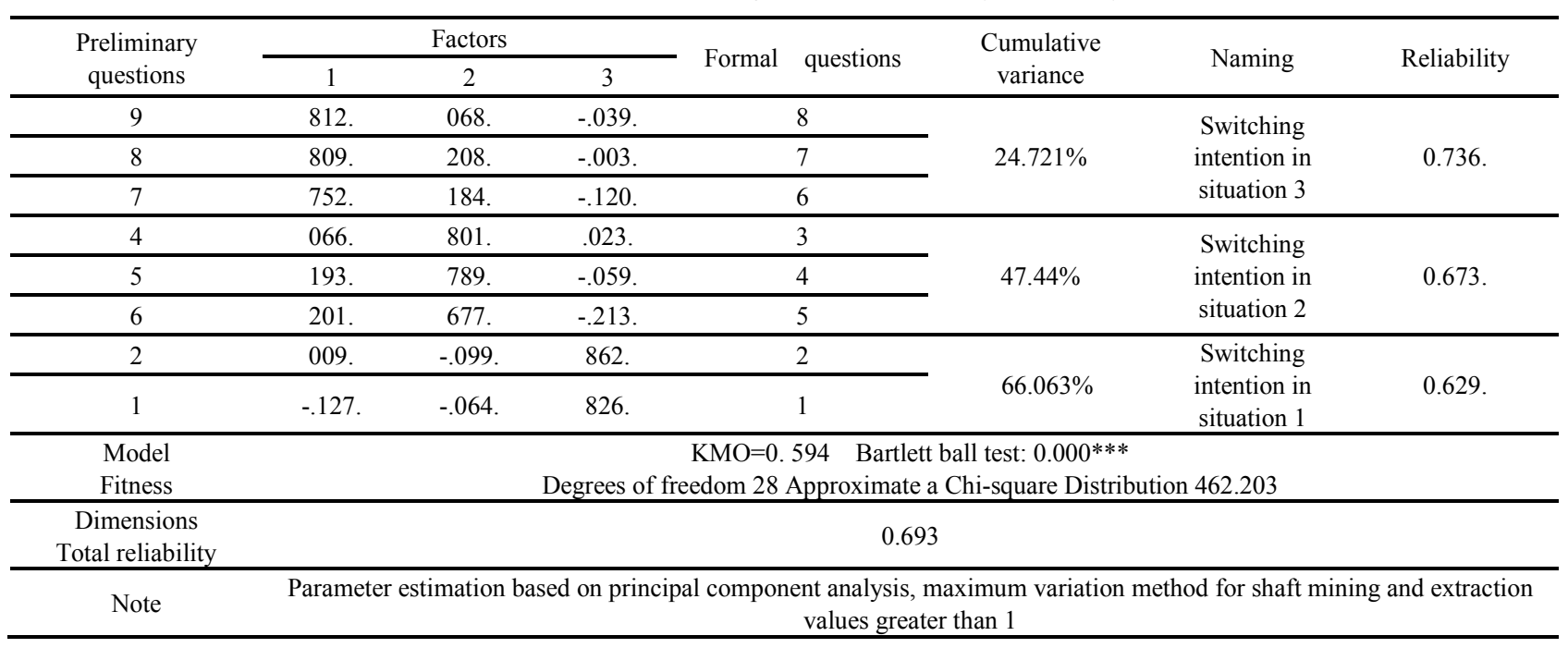

Table 3. Sample background variables

\begin{tabular}{|c|c|c|c|}
\hline Background variables & Category & The number of samples & The percentage $(\%)$ \\
\hline \multirow{5}{*}{ 1. Numbers of join travel packages within the last five years } & 1 & 195 & 47.3 \\
\hline & 2 & 95 & 23.1 \\
\hline & 3 & 46 & 11.2 \\
\hline & 4 & 27 & 6.6 \\
\hline & 5 More than once & 49 & 11.9 \\
\hline \multirow{2}{*}{ 2.Gender } & Male & 190 & 46.1 \\
\hline & Female & 222 & 53.9 \\
\hline \multirow{5}{*}{ 3.Age } & The age of $21-30$ & 65 & 15.8 \\
\hline & The age of $31-40$ & 159 & 38.6 \\
\hline & The age of 41-50 & 141 & 34.2 \\
\hline & The age of 51-60 & 27 & 6.6 \\
\hline & Over the age of 61 & 20 & 4.9 \\
\hline \multirow{4}{*}{ 4. Education } & Junior school & 12 & 2.9 \\
\hline & Senior high schools & 88 & 21.4 \\
\hline & Undergraduate school & 521 & 60.9 \\
\hline & Graduate school & 61 & 14.8 \\
\hline \multirow{7}{*}{ 5.Average monthly income } & 2 & 27 & 6.6 \\
\hline & $2-3$ & 74 & 18.0 \\
\hline & $3-4$ & 102 & 24.8 \\
\hline & $4-5$ & 62 & 15.0 \\
\hline & $5-8$ & 100 & 24.3 \\
\hline & $8-10$ & 22 & 5.3 \\
\hline & More than 10 & 25 & 6.1 \\
\hline \multirow{4}{*}{ 6. Occupation } & Public employment & 68 & 16.5 \\
\hline & Service provider & 56 & 13.6 \\
\hline & Forestry, and animal husbandry & 2 & 0.5 \\
\hline & Workers & 99 & 24.0 \\
\hline \multirow{11}{*}{ 7.Usually entourage with you to participate in overseas tour } & The service industry & 136 & 33.0 \\
\hline & Free job & 15 & 3.6 \\
\hline & Free (Including retirement) & 10 & 2.4 \\
\hline & Other & 26 & 6.3 \\
\hline & Free & 14 & 3.8 \\
\hline & Spouse & 126 & 33.9 \\
\hline & Children & 57 & 15.3 \\
\hline & Parents & 40 & 10.7 \\
\hline & Other relatives & 26 & 7.0 \\
\hline & Friends & 100 & 26.9 \\
\hline & Other & 9 & 2.4 \\
\hline
\end{tabular}


Table 4. Mediated effect of locus of control to service failure situations with customers switching intention

\begin{tabular}{|c|c|c|c|c|c|c|}
\hline $\begin{array}{c}\text { Variable } \\
\text { (Coefficient) }\end{array}$ & 1 & 2 & 3 & 4 & 5 & 6 \\
\hline Locus of control & 27. & 13. & 040. & -.104 & 42. & 331. \\
\hline $\begin{array}{l}\text { Service failure } \\
\text { Situation } 1 \\
\end{array}$ & 26. & 22 & & & & \\
\hline $\begin{array}{l}\text { Service failure } \\
\text { Situation } 2 \\
\end{array}$ & & & $\ldots 47.0^{* * *}$ & $\ldots 423 * * *$ & & \\
\hline $\begin{array}{l}\text { Service failure } \\
\text { Situation } 3\end{array}$ & & & & & $\ldots 452 * * *$ & $\ldots 537 * * *$ \\
\hline $\begin{array}{c}\text { Locus of control, } \\
* \text { Service failure situation } 1\end{array}$ & 14. & & & & & \\
\hline \begin{tabular}{l}
\multicolumn{2}{c}{ Locus of control } \\
*Service $\quad$ failure situation 2
\end{tabular} & & & & 0.152 & & \\
\hline $\begin{array}{c}\text { Locus of control, } \\
* \text { Service failure situation } 3 \\
\end{array}$ & & & & & & -.2 .98 \\
\hline R Square & 001. & 022. & $\ldots 0221 * * *$ & 222. & $\ldots 203 * * *$ & 206. \\
\hline R Squared changed & 001. & 000. & $\ldots 0221 * * *$ & 001. & $\ldots 203 * * *$ & 002. \\
\hline
\end{tabular}

Table 5. Regression analysis of the locus of control to customers switching intention

\begin{tabular}{cccc}
\hline Dependent variable & Switching intention in the situation 1 & Switching intention in the situation 2 & Switching intention in the situation 3 \\
\hline $\begin{array}{c}\text { Explanation } \\
\text { Variable }\end{array}$ & Locus of control & Locus of control & Locus of control \\
\hline Coefficient & 0.53 & 0.72 & 0.70 \\
\hline R Square & 0.03 & 0.05 & 0.05 \\
\hline
\end{tabular}

Table 6. Verification results of research hypotheses

\begin{tabular}{|c|c|c|}
\hline Times & Description & $\begin{array}{c}\text { Verifiable } \\
\text { results }\end{array}$ \\
\hline Hypothesis1 & Service failures will increase consumers switching intention & \\
\hline Hypothesis1-1 & Service failures will increase consumers switching intention in the situation 1 & Not established \\
\hline Hypothesis $1-2$ & Service failures will increase consumers switching intention in the situation 2 & Established \\
\hline Hypothesis 1-3 & Service failures will increase consumers switching intention in the situation 3 & Established \\
\hline Hypothesis2 & Locus of control has a significant effect on consumers switching intention & \\
\hline Hypothesis2-1 & Locus of control has a significant effect on the consumers witching intention in the situation 1 & Not established \\
\hline Hypothesis $2-2$ & Locus of control has a significant effect on the consumer switching intention in the situation 2 & Not established \\
\hline Hypothesis2-3 & Locus of control has a significant effect on the consumer switching intention in the situation 3 & Not established \\
\hline Hypothesis3 & Mediated effect of a service failure on the customer switching intention through locus of control & \\
\hline Hypothesis3-1 & $\begin{array}{l}\text { Mediated effect of a service failure on the customer switching intention through locus of control in the } \\
\text { situation } 1\end{array}$ & Not established \\
\hline Hypothesis3-2 & $\begin{array}{l}\text { Mediated effect of a service failure on the customer switching intention through locus of control in the } \\
\text { situation } 2\end{array}$ & Not established \\
\hline Hypothesis3-3 & $\begin{array}{l}\text { Mediated effect of a service failure on the customer switching intention through locus of control in situation } \\
3\end{array}$ & Not established \\
\hline
\end{tabular}

[2] Bansal, H. S., Irving, P. G. \& Taylor, S. F. (2004). A Three-Component Model of Customer Commitment to Service Providers. Journal of the Academy of Marketing Science, 32(3), 234-250.

\section{REFERENCES}

[1] Athanassopoulos, A., S. Gounaris, and V.Stathakopoulos (2001), "Behavioral Responses to Customer Satisfaction: An Empirical Study", European Journal of Marketing, Vol. 35, pp. 687-707.

[3] Bilgili, B., Candan, B., \& Bilgili, S. (2014). A Research study on the relationship among relational benefit, perceived quality, image and customer loyalty in different hospitality Businesses. International Journal of Management Cases, 16(3), 20-39. 
[4] Chang, K. (2015). How travel agency reputation creates recommendation behavior. Industrial Management \& Data Systems, 115(2), 332-352.

[5] Chou, C., Chen, C., \& Conley, C. (2015). An approach to assessing sustainable product-service systems. Journal of Cleaner Production, 86277-284.

[6] Fuentes, R., \& Alvarez-Suarez, A. (2012). Productivity of travel agencies in Spain: the case of Alicante. Service Industries Journal, 32(16), 2623-2640.

[7] Ganesh, J., J. M. Arnold, and K. E. Reynolds (2000),"Understanding the Customer Base of Service Providers: An Examination of the Differences between Switchers and Stayers", Journal of Marketing, Jul, Vol. 64, No. 3, pp

[8] Ganesh, J., Mark, J. A. \& Kristy, E. R. (2000). Understanding the Customer Base of Service Providers: An Examination of the Differences between Switchers and Stayers. Journal of Marketing, July, 65-87.

[9] Ganesh, J., Mark, J. A. \& Kristy, E. R. (2000). Understanding the Customer Base of Service Providers: An Examination of the Differences between Switchers and Stayers. Journal of Marketing, July, 65-87.

[10] Grace, D. \&O'Cass, A. (2001). Attribution of service switching: a study of consumers and providers perception of child-care service delivery. Journal of Services Marketing, 15(4), 300-321.

[11] Guilford, J. P. (1965). Three faces of intellect. American psychologist, 14(1), 469-479.

[12] Guo Yixin (2011) And tourism and hospitality education in higher technical and vocational students personality, willingness to practice effectiveness and employment related studies, unpublished, meal, National Kaohsiung University, Kaohsiung

[13] He Yongqing, Su Hongren, Lai Wenyi, Lin Tai (2008), the study of consumer switching behavior. Far East journal 25 (1), 179-190.

[14] Hong Limei, and Li Dezhi, and Chen Chunfu, and Li Xuexiu (2010) , Hospitality trainees to related industry intend to study, Journal of hermits, 20 , 46-60

[15] Hu Menglei (2008), Department of hospitality management in vocational college students ' personality characteristics, environment and attitude of the creative industries research, hospitality skills and home economics journal, 5(4), 349-375

[16] Kim, Y., Kim, S., \& Yoo, J. (2012). Travel agency employees' career commitment and turnover intention during the recent global economic crisis. Service Industries Journal, $32(8), 1247-1264$.

[17] Konuş, U., Neslin, S. A., \& Verhoef, P. C. (2014). The effect of search channel elimination on purchase incidence, order size and channel choice. International Journal of Research in Marketing, 31(1), 49-64.

[18] Li Xuexiu (2005), Personality traits and training conditions for hospitality industry invested tourist hotel which influence on the willingness of technical and vocational students graduate: jamming effect of socialization level internship supervisor, unpublished report, National Sun Yat-sen University, Kaohsiung City.
[19] Liao Ruifeng (2005), personality traits, emotional intelligence, influence on job performance, National Central University's Institute of human resource management master's thesis, jhongli city.

[20] Lin Suxing (2011) Service failures on consumers switching intention of the research - Service recovery as an adjustment variable.

[21] Lin Yingling (2006), Personality traits, learning styles and learning styles influence on the effectiveness of, Chaoyang University of technology master's thesis, unpublished, Taichung city.

[22] Ling Yiling (2000) Service contacts research on cognitive script, National Sun Yat-sen Institute of business administration, doctoral thesis, Kaohsiung.

[23] Manhas, P. S., \& Dogra, J. (2013). QUALITY MANAGEMENT PRACTICES AND TOURISM DESTINATION BRANDING: INTER-RELATIONSHIP AND PREFERENTIAL STUDY OF THE COMPONENTS. Journal of Services Research, 13(1), 75-93.

[24] Panda, T. K., \& Das, S. (2014). The Role of Tangibility in Service Quality and Its Impact on External Customer Satisfaction: A Comparative Study of Hospital and Hospitality Sectors. IUP Journal of Marketing Management, 13(4), 53-69.

[25] Parasuraman, A., Zeithaml, V.A., \& Berry, L.L. (1988). SERVQUAL: A Multiple-Item Scale for Measuring Consumer Perceptions of Service Quality. Journal of Retailing, 64(1), 12-40.

[26] Ping, R. A. (1993). The Effects of Satisfaction and Structural Constraints on Retailer Exiting, Voices, Loyalty, Opportunism, and Neglect. Journal of Retailing, 69(3), 321-349.

[27] Priluck, R. (2003), Relationship Marketing Cans Mitigate Product and Service Failures, Journal of Services Marketing, 17 (1), 37-48.

[28] Schoenfeld, B. (2014). THE BEST IN BUSINESS TRAVEL. Entrepreneur, 42(5), 41-48

[29] Spector, P.E.(1987). "Behavior in Organizations as a Function of Employee's Locus of Control." Psychological Bulletin, 91, pp. 482-497.

[30] Tourism Bureau, Republic of China (Taiwan) The Tourism Bureau http://admin.taiwan.net.tw/indexc.asp

[31] Wu Hui (2008), Tourism management, Dongbei University of tourism management master's thesis.

[32] Wu Jinmian (2002) Internal discussion on the current status of medical service and service recovery - a case study of regional hospital in Taoyuan County, Yuan Ze University Management Institute master's thesis.

[33] Ye Riwu (2006) And research on corporate reputation and financial performance, National Dong Hwa University doctoral dissertation in corporate management 。

[34] Yin Yaping (2008), Based on yields of recovery service, Nanjing Normal University, a master's degree thesis.

[35] Zheng Shaocheng ( 1997 ), Service failures, service and customer response, research, International Institute of business administration, Chinese Culture University doctoral 
thesis, unpublished report, Taipei City.

[36] Zhou Bingling ( 2004 ), And service recovery strategies for service failures impact on customer responses - State Road long-distance passenger transport, for example, University Management Institute master's thesis. 